\title{
From adversity to resilience in the COVID-19 era: strengthening mental health systems in the Eastern Mediterranean Region
}

\author{
Julian Eaton, ${ }^{1}$ Atif Rahman, ${ }^{2}$ Richard Gater, ${ }^{3}$ Shekhar Saxena, ${ }^{4}$ Asmus Hammerich ${ }^{5}$ and Khalid Saeed ${ }^{6}$
}

${ }^{1}$ Mental Health Director CBM Global; Assistant Professor, Centre for Global Mental Health, London School of Hygiene and Tropical Medicine, London, United Kingdom. ' 2 Professor of Child Psychiatry and Global Mental Health, University of Liverpool, Child Mental Health Unit Royal Liverpool Children's Hospital, Liverpool, United Kingdom. ${ }^{3}$ Honorary Senior Lecturer in Psychiatry, University of Manchester (retd.), Manchester, United Kingdom. ${ }^{4}$ Professor of the Practice of Global Mental Health, Global Health and Population, Harvard TH Chan School of Public Health, Boston, United States of America. ${ }^{5}$ Director, Department of Noncommunicable Diseases and Mental Health, World Health Organization Regional Office for the Eastern Mediterranean, Cairo, Egypt. ${ }^{6}$ Regional Advisor for Mental Health and Substance Use, World Health Organization Regional Office for the Eastern Mediterranean, Cairo, Egypt. (Correspondence to: Khalid Saeed: saeedk@who.int).

Citation: Eaton J; Rahman A; Gater R; Saxena S; Hammerich A; Saeed K. From adversity to resilience in the COVID-19 era: strengthening mental health systems in the Eastern Mediterranean Region. East Mediterr Health J. 2020;26(10):1148-1150. https://doi.org/10.26719/2020.26.10.1148

Copyright $@$ C World Health Organization (WHO) 2020. Open Access. Some rights reserved. This work is available under the CC BY-NC-SA 3.0 IGO license (https://creativecommons.org/licenses/by-nc-sa/3.o/igo)

The global COVID-19 pandemic has demonstrated the impact of a major public health emergency on mental health, and the ways that individuals, communities, professionals and systems can react positively to such a crisis. The Eastern Mediterranean Region (EMR) has substantial experience in mental health and psychosocial support (MHPSS) in crises (1,2), and COVID-19 has driven further innovation to support mental health and well-being.

Global and regional guidance has been developed quickly, applying lessons learnt from previous disease outbreaks $(3,4)$ to respond to the pandemic at a systems level (5), for different population groups (6), and for countries of different income levels (7). Preliminary results from a global rapid assessment survey to assess the impact of COVID-19 on MHPSS services, indicate that 20 of the 22 EMR Member States have MHPSS as integral components of national COVID-19 response plans; one-third have allocated additional funding. However, MHPSS services have been severely impacted by the pandemic, including psychotherapy, psychosocial interventions, community services, and services for children/adolescents. Innovative solutions such as crisis hotlines, tele-consultations, digital self-help platforms, novel approaches to ensure supply of psychotropic medicines, and task sharing/shifting for basic psychosocial support, are being used in many countries to overcome service disruptions and maintain care for those with mental conditions (8).

The raised profile of mental health in an emergency is an opportunity to "Build Back Better" (9) on foundations of recent progress in mental health. The Regional Framework, aligned to the global Mental Health Action Plan (2013-2030), was adopted in 2015 (10), and mental health and substance use interventions have been incorporated in Universal Health Coverage (UHC) packages. Such progress is crucial in realizing the World Health Organization's (WHO) ambitious 'triple billion target' (1 billion more people benefitting from UHC, 1 billion more people better protected from health emergencies and 1 billion more people enjoying better health and well-being) (11). Here we outline key issues and opportunities - recognizing features of the Region such as a growing youth population, income disparities and complex humanitarian emergencies leading to large scale internal displacement and migration (12).

First, global mental health has increasingly recognized social determinants of mental health (13). The link with poverty is well described (14), and during periods of economic depression, rates of mental illness increase (15). It is likely that the long-term economic impact of COVID-19 will have substantial mental health consequences. The mental health community must capitalize on the interest in mental health during the pandemic, garnering political will to increase investment in policies that reduce poverty, and inequities in education, access to health, employment and housing.

Second, access to mental health care is poor, and there is need to rebalance resources so that investment in mental health care reflects the high proportion of burden of disease that it represents (16). Most EMR countries invest less than $1 \%$ of their health budget on mental health; $80 \%$ of this investment is in psychiatric hospitals, and there are over ten times as many psychiatric hospital beds than more accessible psychiatric beds in general hospitals (17). Policy and systems reform is necessary to increase efficiency and equity of resource use $(11,18)$. Integration of mental health into general health systems, as part of efforts to achieve UHC, is likely to be the most effective way of increasing access to services using strategies such as "task-shifting" (18).

Services for young people, including promotion and prevention, is another crucial issue. Seventy-five percent of all mental conditions commence before the age of 25 , but investment in young peoples' mental health is extremely limited (19) and could be critical in the postCOVID-19 era. There are, however, excellent examples of initiatives addressing child mental health in the Region; for example, the School Health Implementation Network in the Eastern Mediterranean Region (SHINE) is scalingup a schools-based intervention that empowers teachers to assist students and parents affected by adversity (19). 
Finally, there is a close relationship between population wellbeing and behaviour. Marginalized groups, like persons with mental health conditions, migrants and displaced people are less likely to receive public health messages, for example about vaccine uptake (20), and are therefore exposed to greater risk. Attention must be paid to ensure marginalized groups, who have increased risk of mental conditions, are included in emergency planning and able to access public health information, if countries are to be resilient to future crises (21). Frontline workers including health care workers are another group at increased risk of mental distress, burnout, and substance use. The WHO Eastern Mediterranean Regional Office (EMRO) Mental health and social support platform has been developed to support people with psychosocial difficulties and counter misinformation, including a special section for frontline workers with evidence-based resources to help them deal with the stress they are feeling during the COVID-19 pandemic (22).

New technologies to support public health messaging and accessible interventions have shown enormous potential during the pandemic. Still, these are not a comprehensive replacement for traditional face to-face services, and are themselves inaccessible to certain populations (23).

An excellent way to improve mental health is to focus on reducing social inequity through an integrated community-oriented system of care operating across health and social care systems, supported by operational research to guide implementers and policy-makers to deal with current and future challenges. This requires political will at the highest policy-making level, and an increase in resources at all levels of the health and social care systems $(21,24)$.

As we enter the last 10 years of the Sustainable Development Goals era, the shock of the COVID-19 pandemic provides an opportunity to reassert the messages of recent learning in global mental health. A future where the Region is resilient to shocks such as pandemics, migration, and climate change, will depend on systematic consideration of mental health and wellbeing in health systems, development processes, and humanitarian response.

\section{References}

1. Karam E, El Chammay R, Richa S, Naja W, Fayyad J, Ammar W. Lebanon: mental health system reform and the Syrian crisis. BJPsych. International, 2016;13(4):87-89.

2. Brennan R, Hajjeh R, Al-Mandhari A. Responding to health emergencies in the Eastern Mediterranean region in times of conflict. Lancet. 2020 Mar 2 doi: 10.1016/So140-6736(20)30069-6 [Epub ahead of print].

3. Van Bortel T, Basnayake A, Wurie F, Jambai M, Koroma AS, Muana AT, et al. Mental health consequences of Ebola. Bull World Health Organ. 2016;94(3):210-214.

4. Inter-Agency Standing Committee (IASC). Interim Briefing Note Addressing Mental Health and Psychosocial Aspects of COVID-19 Outbreak (developed by the IASC's Reference Group on Mental Health and Psychosocial Support)| IASC [Internet]. 2020 (https://interagencystandingcommittee.org/iasc-reference-group-mental-health-and-psychosocial-support-emergency-settings/ interim-briefing)

5. World Health Organization. Mental health and psychosocial considerations during the COVID-19 outbreak, 18 March 2020. Geneva: World Health Organization, 2020 (https://www.who.int/docs/default-source/coronaviruse/mental-health-considerations. pdf).

6. Mental Health Innovation Network (MHIN). COVID-19 Resources by Population Group. London: London School of Hygiene and Tropical Medicine; 2020 (https://www.mhinnovation.net/resources-population-group).

7. Maulik PK, Thornicroft G, Saxena S. Roadmap to strengthen global mental health systems to tackle the impact of the COVID-19 pandemic. Int J Ment Health Syst. 2020;14(1):1-13.

8. Hamilton A. Stories from the field: mapping innovation in mental health during the COVID-19 pandemic. Intervention, 2020

9. World Health Organization. Building back better: sustainable mental health care after emergencies. Geneva: World Health Organization; 2013 (https://www.who.int/mental_health/emergencies/building_back_better/en/).

10. Alwan A, Saeed K. A new agenda for mental health in the Eastern Mediterranean Region. East Mediterr Health J. 2015;21(7):459460. https://doi.org/10.26719/2015.21.7.459

11. World Health Organization. The WHO special initiative for mental health (2019-2023): universal health coverage for mental health. Geneva: World Health Organization; 2019 (https://apps.who.int/iris/handle/10665/310981).

12. World Health Organization Regional Office for the Eastern Mediterranean (WHO/EMRO). COVID-19 strategic preparedness and response plan: strengthening the collective response and accelerating readiness in the Eastern Mediterranean Region - July 2020 edition. Cairo: WHO/EMRO; 2020.

13. Patel V, Saxena S, Lund C, Thornicroft G, Baingana F, Bolton P, et al. The Lancet Commission on global mental health and sustainable development. The Lancet, 2018;392(10157):1553-1598.

14. Lund C, De Silva M, Plagerson S, Cooper S, Chisholm D, Jishnu D, et al. Poverty and mental disorders: breaking the cycle in low-income and middle-income countries. The lancet. 2011;378(9801):1502-1514. 
15. Hong J, Knapp M, McGuire A. Income-related inequalities in the prevalence of depression and suicidal behaviour: a 10-year trend following economic crisis. World Psychiatry. 2011;10(1):40.

16. GBD Eastern Mediterranean Region Mental Health Collaborators. The burden of mental disorders in the Eastern Mediterranean region, 1990-2015: findings from the global burden of disease 2015 study. Int J Public Health. 2018;63(1):25-37.

17. World Health Organization Regional Office for the Eastern Mediterranean (WHO/EMRO). Mental health atlas 2017: resources for mental health in the Eastern Mediterranean Region. Cairo: WHO/EMRO; 2017 (https://apps.who.int/iris/handle/10665/327491).

18. Saxena S, Thornicroft G, Knapp M, Whiteford H. Resources for mental health: scarcity, inequity, and inefficiency. Lancet, 2007;370(9590):878-89.

19. Hamdani SU, Huma ZE, Warraitch A, Suleman N, Mazzafar N, Minhas FA, et al. Technology-assisted teachers' training to promote socioemotional well-being of children in public schools in rural Pakistan. Psychiatric Services, 2020 (https://doi.org/10.1176/ appi.ps.202000005).

20. Thorpe JM, Kalinowski CT, Patterson ME, Sleath BL. Psychological distress as a barrier to preventive care in community-dwelling elderly in the United States. Med Care. 2006 Feb;44(2):187-91. doi: 10.1097/01.mlr.0000196965.54871.d5.

21. Weissbecker I, Roshania R, Cavallera V, Mallow M, Leichner A, Antigua J, et al. Integrating psychosocial support at Ebola treatment units in Sierra Leone and Liberia. Intervention. 2018;16(2):69.

22. World Health Organization Regional Office for the Eastern Mediterranean (WHO/EMRO). Mental health and psychological support. Cairo: WHO/EMRO; 2020 (http://www.emro.who.int/mhps/frontline_worker.html).

23. Moreno C, Wykes T, Galderisi S, Nordentoft M, Crossley N, Jones N, et al. How mental health care should change as a consequence of the COVID-19 pandemic. The Lancet Psychiatry. 2020;7(9):813-824 https://doi.org/10.1016/S2215-0366(20)30307-2

24. Wilkinson RG, Pickett K. The spirit level: why more equal societies almost always do better. London: Allen Lane; 2009. 